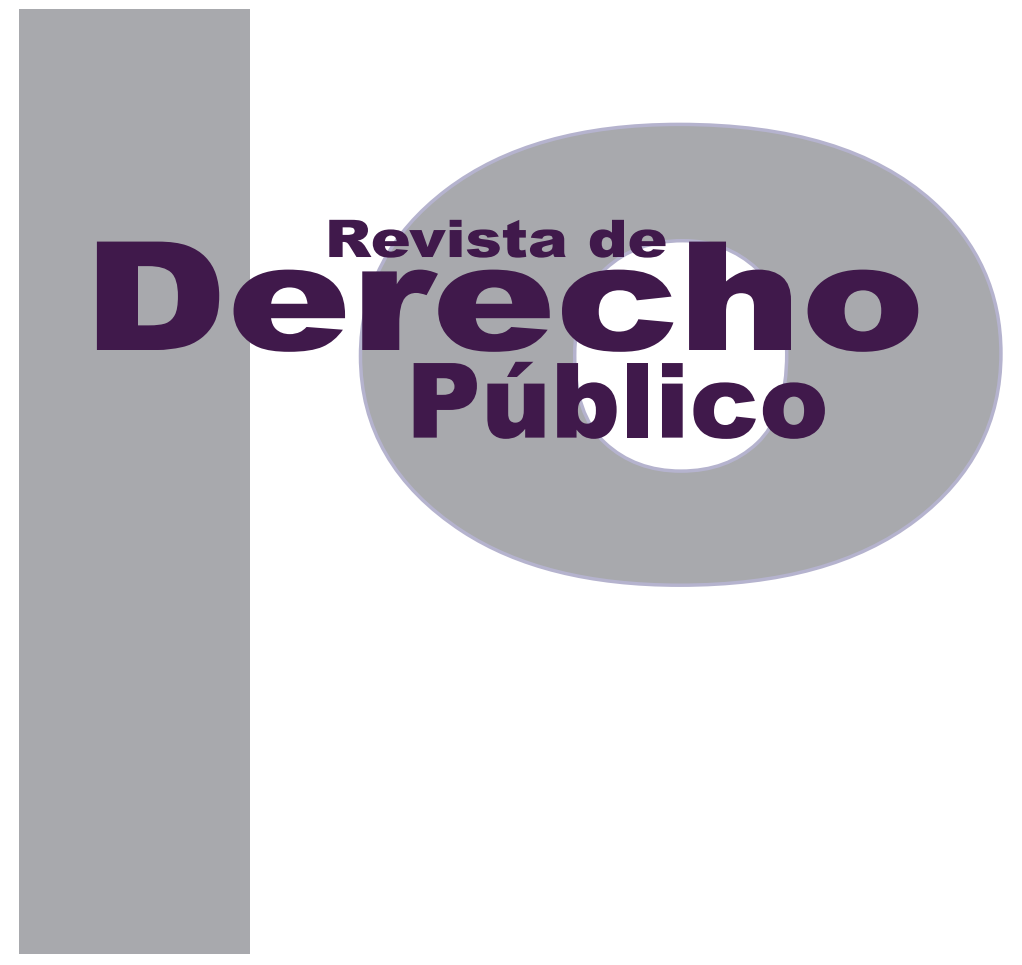

\title{
El Plan de Salvaguarda para el pueblo wayuu EN RIOHACHA. DESAFÍOS Y ESPERANZAS
}

\author{
EDWIN RUBIO MEDINA
}

\author{
Reporte de caso
}

DOI: http://dx.doi.org/10.15425/redepub.34.2015.14

Universidad de los Andes

Facultad de Derecho

Revista de Derecho Público N. ${ }^{\circ} 34$

Enero - Junio de 2015. ISSN 1909-7778 


\section{El Plan de Salvaguarda para el pueblo wayuu en Riohacha. Desafíos y esperanzas.}

\section{Resumen}

En este estudio se pretende hacer una aproximación a la definición, características e implicaciones que tuvo el auto 004 de 2009 de la Corte Constitucional en la regulación del fenómeno del desplazamiento forzado de las comunidades indígenas, particularmente para el pueblo wayuu que se encuentra asentado en Riohacha. El trabajo se realizó con los Ilamados territorios ancestrales, es decir, aquellas comunidades a las que no se les ha dado el reconocimiento de resguardo. Durante dos meses se hizo un trabajo de campo con un enfoque cualitativo, cuyo objeto fue identificar cuáles son las principales afectaciones producidas directa e indirectamente por el conflicto armado, de acuerdo con lo establecido por el mencionado auto, en algunos de los contextos más importantes. Posteriormente se analizaron dichas afectaciones, teniendo en cuenta algunas reflexiones en relación con la eficacia y puesta en marcha del Plan de Salvaguarda para el pueblo wayuu. Es relevante señalar que los planes de salvaguarda protegen 34 pueblos en peligro de extinción física y cultural. Por tanto, se protege a la etnia en su conjunto, es decir, que a pesar de que la más grave violación de los derechos humanos contra el pueblo wayuu fue la masacre de Bahía Portete, lugar ubicado en el municipio de Uribia, se debe diseñar un Plan de Salvaguarda en cada municipio donde habitan los indígenas wayuu en la Guajira, por ende este artículo se centra en el capítulo Riohacha. Finalmente se presentan algunas conclusiones sobre si el Plan de Salvaguarda wayuu contribuye o no a la preservación cultural y física de la etnia más numerosa del país. Ante lo cual considero importante pero insuficiente la iniciativa, como lo muestran los incumplimientos estatales.

Palabras clave: pueblo wayuu, jurisdicción especial indígena, conflicto armado, desplazamiento forzado, plan salvaguarda, auto 004 de 2009 , Corte Constitucional.

\section{Safeguarding plan for the wayuu people. Challenges and hopes}

\section{Abstract}

This article pretends to make an approach to the definition, characteristics and implications that sentence number 004 of Constitutional Court had on the regulation of the phenomenon of indigenous communities forced displacement, in particular for the wayuu people living in Riohacha. This work was carried out with the so-called ancestral territories, referring to those communities that have not been given the recognition of shelter. During two months, a qualitative field work was conducted, in order to identify the main affectations produced directly and indirectly by the armed conflict on this group, according to the provisions of the mentioned sentence. With some of the most important contexts, an analysis of these affectations was done, considering some reflections related to start up and efficacy of wayúu people safeguarding plan. It is relevant to mention that the safeguard plans protect 34 physical and culturally endangered indigenous people in Colombia. Therefore these plans protect ethnicity as a whole, meaning in our case that even when Bahia Portete massacre, occurred in Uribia municipality, has been one of the most known human rights violations against wayuu people, a safeguarding plan must be designed in each of the municipalities of the Guajira Department in which wayuu people inhabit; this article focus on the Riohacha chapter, and finally concludes with some reflections about if indeed wayuu safeguarding plan contributes or not, to the cultural and physical preservation of the country's largest ethnic group. I consider important but insufficient the propose of safeguard plan as shown the state failure.

Keywords: wayuu people, special indigenous jurisdiction, armed conflict, forced displacement, safeguard plan, sentence 004, 2009, Constitutional Court.

\section{O Plano de Salvaguarda para o povo wayuu em Riohacha. Desafios e esperanças}

\section{Resumo}

Neste estudo se pretende fazer uma aproximação da definição, características e implicações que teve o auto 004 de 2009 da Corte Constitucional na regulação do fenômeno do deslocamento forçado das comunidades indígenas, particularmente para o povo wayuu que se encontra assentado em Riohacha. 0 trabalho foi realizado com os chamados territórios ancestrais, ou seja, aquelas comunidades que não receberam reconhecimento de resguardo. Durante dois meses, foi feito um trabalho de campo com um enfoque qualitativo, cujo objetivo era identificar quais são as principais afetações produzidas direta e indiretamente pelo conflito armado, de acordo com o estabelecido pelo mencionado auto, em alguns dos contextos mais importantes. Posteriormente, foram analisadas ditas afetações, considerando algumas reflexões em relação com a eficácia e desenvolvimento do Plano de Salvaguarda para o povo wayuu. É relevante sinalar que os planos de salvaguarda protegem 34 povos em perigo de extinção física e cultural. Portanto, se protege a etnia em seu conjunto, ou seja, apesar da mais grave violação dos direitos humanos contra o povo wayuu, o massacre de Bahía Portete, lugar localizado no município de Uribia, se deve desenhar um Plano de Salvaguarda em cada munícipio onde habitam os indígenas wayuu na Guajira, assim este artigo se centra no capítulo Riohacha. Finalmente se apresentam algumas conclusões se o Plano de Salvaguarda wayuu contribui ou não para a preservação cultural e física da etnia mais numerosa do país. Ante o qual considero importante, mas a iniciativa é insuficiente, como mostram os incumprimentos estatais.

Palavras-chave: povo wayuu, jurisdição especial indígena, conflito armado, deslocamento forçado, plano salvaguarda, auto 004 de 2009, Corte Constitucional. 


\title{
El Plan de Salvaguarda para el pueblo wayuu en Riohacha. Desafíos y esperanzas*
}

\author{
Edwin Rubio Medina**
}

\section{SUMARIO}

Introducción - I. CARACTERIZACIÓN DEL PUEBLO WAYUU - A. ¿Quiénes son los wayuu? - B. ¿Quiénes son los contemporáneos wayuu? - C. ¿Qué significa un territorio ancestral? - D. ¿Quiénes habitan los territorios ancestrales? - E. ¿Por qué el pueblo wayuu fue incluido en el auto 004 de 2009? - F. Contexto social y político que originó el auto 004 de 2009 - G. Implicaciones del auto 004 de 2009 para los indígenas - H. ¿Qué dice el auto 004 de 2009 ? - I. Cumplimiento del auto 004 de 2009 - II. METODOLOGÍA - A. Para el trabajo de campo - B. Instrumentos de socialización y diagnóstico auto 004 de 2009 - 1. La entrevista (sakirra) semiestructurada - 2. Cartografía social 3. Ventaja de la cartografía social (shiakua wouumaiinpa) - III. RESULTADOS EN EL PROCESO DE INVESTIGACIÓN - A. Categoría 1. Las confrontaciones que se desenvuelven en territorios indígenas entre los actores armados, sin involucrar activamente a las comunidades indígenas y sus miembros, pero afectándolos en forma directa y manifiesta - B. Categoría 2. Los procesos bélicos que involucran activamente a los pueblos y comunidades indígenas, y a sus miembros individuales, en el conflicto armado - C. Categoría 3. Los procesos territoriales y socioeconómicos conexos al conflicto armado interno que afectan sus territorios tradicionales y sus culturas - 1. Punto de vista violento - 2 . Punto de vista no violento - D. Categoría 4. Procesos socioeconómicos que, sin tener relación directa con el conflicto armado, resultan exacerbados o intensificados por causa de la guerra - IV. CONCLUSIONES - Referencias.

* $\quad$ Cómo citar este artículo: Rubio Medina, E. (Junio, 2015). El Plan de Salvaguarda para el pueblo wayuu en Riohacha. Desafíos y esperanzas. Revista de Derecho Público, 34. Universidad de los Andes (Colombia).

** Abogado defensor de DD. HH., especialista en Docencia Universitaria, candidato a magíster en DD. HH. y Democratización, Universidad Externado de Colombia. Correo: edwinabogadofos@gmail.com 
Introducción

Este artículo de investigación no habría sido posible sin la colaboración de los líderes wayuu vinculados con el Plan de Salvaguarda, a través de la organización de autoridades ancestrales AKALINIRA WA. ${ }^{1}$ Para ellos toda mi gratitud y reconocimiento por su decidida tarea de preservar la cultura wayuu (Wakuaipa), en medio de los procesos de occidentalización, violencia social y política, y las precariedades socioeconómicas atribuibles, en mi opinión, a la corrupción y la ausencia estatal.

Me propongo en primer lugar caracterizar quiénes son los wayuu, enfocándome en quienes actualmente habitan los territorios ancestrales de Riohacha, haciendo un breve repaso histórico que puede ser útil para comprender la complejidad del sistema social guajiro y las carencias estatales existentes. Posteriormente haré un breve resumen del contexto social y político en el que se origina el auto 004 de 2009, valorando las posibles implicaciones que trajo para las comunidades indígenas, especialmente para el pueblo étnico más septentrional de Colombia, y valorar el cumplimiento efectivo de este mandato legal.

En este orden de ideas, continuaré explicando la metodología cualitativa, conjuntamente con los instrumentos de investigación utilizados en la obtención de la información que se requirió

1 Fundación por la que he sido contratado para acompañar a las comunidades ancestrales del pueblo wayuu en Riohacha, y que me permitió visitar 65 rancherías durante dos meses de trabajo de campo, sin embargo, las apreciaciones personales, análisis y conclusiones son de mi autoría. para realizar el diagnóstico, tratando constantemente de representar la voz auténtica de los wayuu. Así mismo, esta caracterización permite evidenciar la relación entre las necesidades y problemáticas de este pueblo y los cuatro grados de afectación que trae el auto 004 de 2009, el cual se constituye en la columna vertebral del Plan de Salvaguarda.

Posteriormente paso a explicar los resultados de esta investigación que partió de valorar la información suministrada por las comunidades a través de sus relatos, historias, vivencias, preocupaciones, así como las posibles soluciones que la comunidad planteó ante la grave crisis humanitaria que hoy padece (Guerrero, 2014, pág. 5).

Finalmente presentaré las conclusiones de esta investigación desde mi punto de vista frente a los hallazgos encontrados; opiniones que pretendo compartir con los miembros de los territorios ancestrales wayuu que tan amablemente me han permitido conocer su sentir y su cosmogonía.

\section{CARACTERIZACIÓN DEL PUEBLO WAYUU}

\section{A. ¿Quiénes son los wayuu?}

Es mucha la literatura etnográfica que existe sobre el pueblo wayuu y particularmente sobre su sistema de justicia. Entre las más importantes se destaca el ensayo de Benson Saler, Principios de compensación y el valor de las personas en la sociedad guajira, publicado en Caracas en 1986, donde caracteriza los sistemas de com- 
pensación, los giros idiomáticos, así como la conformación sociopolítica. Otro relevante aporte es el realizado por Miguel Perrin en su ensayo "La ley guajira: justicia y venganza entre los guajiros", publicado en el número 9 de la revista Cenipec, en que expone los cambios sociales y económicos sufridos por los wayuu en el siglo XX y plantea crear un código que establezca respuestas ante las afectaciones económicas y sociales originadas entre los mismos wayuu.

Para la caracterización de quién es el pueblo en estudio usé como referencia algunas de las ideas del antropólogo wayuu Weilder Guerra, para quien según los datos históricos en el siglo XVI en La Guajira coexistían distintos grupos indígenas, entre los que se contaban los guanebucanes, coanaos, anates, caquetios, eneales, onotos, macuiras y cocinas (Guerra, 2002, pág. 49).

En el siglo XVII se presentó un cambio significativo en el tránsito del nomadismo de algunos pueblos indígenas, pasando por la agricultura de los apalanchi - como los wayuu llaman a los costeros que viven de la pesca-, Ilegando a la ganadería y constituyéndose desde entonces como un pueblo pastoril; este nuevo escenario generaría profundas desigualdades sociales, así como una representación de la estratificación social vigente hasta hoy.

\section{Según lo explica Picón:}

En el mismo siglo XVII se comenzó a generar un proceso de comercialización de las perlas guajiras del mar caribe con las Antillas, dicha circunstancia bien puede ser un elemento para comprender cómo en el departamento se han vivido procesos de intercambio comercial, legal e ilegal, siendo un detonante de conflictos sociales y económicos que terminó con la presencia de los autores armados que luchaban por el control territorial, rutas del narcotráfico, recursos naturales no renovables (1996, pág. 307).

\section{B. ¿Quiénes son los contemporáneos wayuu?}

Teniendo como referente a Guerra (2002, pág. 47), los principales aspectos sociodemográficos serían:

El área que actualmente ocupa la población Wayúu comprende toda la península de la Guajira y tiene como límite oriental al Golfo de Coquibacoa o de Venezuela y como límite occidental a la Boca de Camarones y laguna de $\mathrm{Na}$ vio Quebrado situadas en la vertiente nororiental de la Sierra Nevada de Santa Marta; al sur los últimos asentamientos tradicionales Wayuu se encuentran cerca a los cursos medio y bajo de los ríos Ranchería y Limón en Colombia y Venezuela respectivamente. Al presente, los Wayuu se han extendido a las zonas urbanas de Maracaibo, a la Serranía de Perijá y a otras áreas rurales del estado del Zulia, asimismo, importantes núcleos de familias indígenas residen en sectores urbanos de Riohacha, Manaure, Maicao y Uribia en el departamento de La Guajira.

De conformidad con los datos provistos por el Censo Binacional de 1992 los Wayuu constituyen el grupo indígena más numeroso de CoIombia y Venezuela. Sus miembros llegaban en ese año a 297.454 personas de las cuales $128.727(43,3 \%)$ se encontraban en el lado 
colombiano de la península y 168.727 (56,7\%) habitaban en el lado venezolano. La población femenina de la etnia en Colombia corresponde al $52.2 \%$ del total de la población. El 57,6\% de la población Wayuu es menor de veinte años.

El siglo XX se ha caracterizado por un aumento en la proyección ideológica, política, demográfica, económica y militar de los estados nacionales de Colombia y Venezuela hacia el territorio ancestral Wayuu. Dicho proceso iniciado desde el siglo XIX había buscado el quebrantamiento de la resistencia indígena frente a los procesos de reducción de la autonomía política del Pueblo Wayuu. No obstante, el proceso de colombianización o venezolanización de este grupo indígena puede considerarse inconcluso. Al lado de las formas tradicionales de conciliación se aplican las legislaciones nacionales colombiana y venezolana presentándose un pluralismo jurídico de hecho que empieza a ser reconocido, al menos formalmente, por la normatividad colombiana y venezolana. La presencia de los organismos judiciales y policiales ha menoscabado la autonomía política y cultural de la cual gozaron los indígenas de la península durante siglos. No obstante, al mismo tiempo nuevas formas de interlocución y organización han aparecido las cuales han coadyuvado a que muchas organizaciones comunitarias se movilicen para la inclusión y aplicación de derechos plasmados en la legislación indígena de las dos repúblicas.

\section{C. ¿Qué significa un territorio ancestral?}

Siguiendo el trabajo de Herreño (2004, pág. 10), los Ilamados territorios ancestrales se encuentran enmarcados dentro del reconocimiento del derecho colectivo a la tierra, por parte de las comunidades indígenas que han tenido asiento desde mucho tiempo atrás y así lo ha venido ratificando la Corte Constitucional colombiana en varios fallos judiciales. ${ }^{2}$ Este reconocimiento debe entonces terminar con un proceso de adjudicación de título de propiedad, como una garantía del desarrollo cultural, político y social, sin desconocer que este puede parecer confuso y ajeno a las cosmogonías del ser indígena, es decir, se convierte la adjudicación de las tierras y la adhesión a un resguardo constituido en un requisito exigido por el Estado colombiano, como bien lo reseña Jaramillo (2003, pág. 15).

Dicho fenómeno se pone en evidencia para el caso wayuu, ya que hasta hace poco tiempo el concepto de resguardo era irrelevante puesto que no pertenece a la forma como se constituye la autoridad política y social en La Guajira, que como mencioné antes se produce a través de la figura de la autoridad tradicional de una ranchería (apüshii).

\section{D. ¿Quiénes habitan los territorios ancestrales?}

Este aparte se basa en la información obtenida en la entrevista realizada a Carlos Uriana, autoridad ancestral de la comunidad de Campoalegre y líder del proceso para la constitución del resguardo desde el año 1997.

El territorio señalado es extenso y se ubica en diferentes sectores del municipio, de la siguiente manera: vía Santa Marta, vía Valledupar, vía

2 Véase, como ejemplo, la sentencia SU-039 de 1997 
acueducto de Riohacha (aquí se encuentran rancherías dentro y fuera del casco urbano de la capital).

La lucha emprendida por los actores sociales wayuu en Riohacha comienza en el año 1997; para esta época el municipio desconocía a más de 154 rancherías como territorios indígenas ancestrales, y existen todavía cerca de otras 100 que no cuentan con reconocimiento por parte de la Alcaldía de la capital de La Guajira. Igualmente, no existía autonomía ni recursos para estos pobladores por parte de las entidades estatales, fue después de una larga lucha que se configuró un equipo de trabajo que promovió el reconocimiento como territorio resguardado en Riohacha. La posición inicial de la Alcaldía consistió en reconocer solo siete resguardos en la ciudad: Alta y Media, Las Delicias, Monte Harmón, Soldado Párate Bien, Unacho, Perralta y Maniature, todos a partir del año 1993. El concepto de resguardo es ajeno a la cultura wayuu, ya que ellos siempre manejaron la noción de territorio a partir de la residencia del tío materno de una comunidad. Finalmente, luego del apoyo brindado por la Oficina del Alto Comisionado de las Naciones Unidas para los Refugiados (ACNUR) a los territorios ancestrales desde el año 2002 hasta el 2005, los líderes de la zona realizaron un censo poblacional y caracterizaron los contextos de sus comunidades, logrando el reconocimiento del territorio como ancestral por parte del municipio, con la verificación del Ministerio del Interior. Sin embargo el proceso para la adjudicación y constitución como resguardo no ha concluido, y actualmente se espera que el Instituto Colombiano de Desarrollo Rural (INCO-
DER) realice un estudio etnográfico para avalar estos terrenos como un resguardo adicional a los ya mencionados. El paso final consiste en consultar a las comunidades sobre si existe o no interés en constituirse en resguardo. Para Carlos Uriana, entre los principales beneficios de constituirse como resguardo está la distribución de recursos por regalías - esencial debido a las difíciles condiciones socioeconómicas que afrontan los territorios no resguardados-, además de impedir la venta y compra de terrenos considerados colectivos que tantos conflictos han generado entre los habitantes de territorios ancestrales y los alijuna, es decir, los no wayuu.

\section{E. ¿Por qué el pueblo wayuu fue incluido en el auto 004 de 2009?}

El referente principal en materia de violencia, atribuible al conflicto armado interno en La Guajira, es sin lugar a duda la masacre de Bahía Portete. Sin embargo, el clima de violencia contra los wayuu en todo el departamento es evidente, por ello presento algunos datos estadísticos relacionados con la presencia de los actores armados. Para ello me sustento en el Diagnóstico de la situación del pueblo indígena wayúu, del Observatorio del Programa Presidencial de Derechos Humanos y DiH (2010, pág. 3).

El primer contexto de violencia sociopolítica tiene los siguientes hitos:

El modus operandi de los grupos armados ilegales en esta zona estuvo relacionado inicialmente con la bonanza marimbera de la década de los setenta. Posteriormente, las FARC, con los frentes 41 Cacique Upar, 19 y 59 Resistencia 
Wayuu y el ELN con los frentes Luciano Ariza y Gustavo Palmesano, comenzaron a actuar en la zona para establecer un dominio territorial y un control social basado en las contribuciones económicas obligatorias, los homicidios selectivos, los secuestros y la intimidación; para finales de los noventa, varios grupos de autodefensa, especialmente las autodefensas del Mamey, del bloque Norte de las auc dirigidas por José María Barros, alias Chema Bala, comenzaron a disputarle a las guerrillas de las FARC $y$ el ELN el control de la zona y a obstaculizar el aprovisionamiento de insumos, tales como armas.

Finalmente, las Auc lograron una notable influencia en la zona que resultó en el repliegue de la guerrilla hasta la Sierra Nevada de Santa Marta y la serranía del Perijá.

A partir del año 2000, la violencia en la zona se intensifica debido a la confrontación por el dominio de la zona, entre las estructuras del narcotráfico, la guerrilla, y las autodefensas. Salvo los años 2003, 2004 y 2008, los contactos armados adelantados por la Fuerza Pública siempre superaron las acciones armadas perpetradas por los grupos armados irregulares.

El progresivo incremento en los contactos armados entre 2004 y 2006 podría estar relacionado con la instalación de la Décima Brigada Blindada del Ejército en los departamentos de Cesar y La Guajira, para retomar el control de la zona. A lo largo del período en estudio, se registró un total de 74 contactos armados desarrollados por parte de la Fuerza Pública. En la región habitada por el pueblo Wayúu, los contactos armados promovidos por la Fuerza Pública experimentaron un incremento del $257 \%$ entre 2003 y 2006 , cuando se presentó el pico del período, mientras que entre 2006 y 2008 descendieron en un $80 \%$, al pasar de 25 a 5 contactos en el último año.

Por otra parte, las acciones de los grupos armados al margen de la ley no registraron variaciones tan significativas, con excepción de lo sucedido entre 2005 y 2006 , cuando subieron en un $180 \%$, pasando de 5 a 14 para luego descender en 2007 en un $57 \%$. Entre 2003 y 2008 , el $80 \%$ (59) de los contactos armados se presentaron en los municipios de Riohacha (27), Maicao (22) y Fonseca (10).

De lo anteriormente expuesto se puede inferir que en los últimos años los principales actores armados que han afectado al pueblo wayuu han sido los integrantes de la fuerza pública y los grupos paramilitares (sobre todo hasta 2007), bien sea en acciones de cada uno de ellos o acciones en conjunto.

Los planes salvaguardas deben entenderse desde la unidad del pueblo indígena. Esto quiere decir que a pesar de que Bahía Portete es el principal hecho victimizante contra los wayuu en los últimos tiempos, la Corte Constitucional considera que en su conjunto la etnia presenta un riesgo de extinción física y cultural. Por cuestiones metodológicas se han dividido los territorios en el departamento de La Guajira, y mi investigación está centrada en los hallazgos encontrados en el Plan de Salvaguarda capítulo Riohacha. 


\section{F. Contexto social y político que originó el auto 004 de 2009}

La violencia sociopolítica contra las comunidades indígenas en el país es algo recurrente a lo largo de la historia. Sin embargo, entre el 2002 y el 2009, según la Organización Nacional Indígena de Colombia (onıc, 2009, pág. 10) más de 1000 indígenas fueron asesinados por causas violentas, siendo los pueblos más afectados: nasa, wayuu, kankuamo, awá y embera chamí. También, según las estadísticas de la Corporación Colectivo de Abogados José Albear Restrepo (cCAJAR, 2009, pág. 25), de los asesinatos al menos un $15 \%$ eran mujeres, niños y niñas; en ese mismo periodo se calcula que 176 indígenas fueron víctimas de violencia sexual y tortura, y 633 indígenas sufrieron detenciones arbitrarias.

De acuerdo con cCAJAR (2009), durante el año 2008 fueron asesinados 99 indígenas y otros 25 en el primer semestre del 2009. En los últimos años se registran 5000 amenazas contra los pueblos indígenas y sus organizaciones. Entre 2002 y 2009 se denunció que 84 indígenas habrían sido víctimas de ejecuciones extrajudiciales y en al menos 10 casos son atribuibles directamente a la fuerza pública.

Según la Corporación para la Defensa y Promoción de los Derechos Humanos (Reiniciar, 2009), otra circunstancia importante para expedir el auto 004 de 2009 fueron las múltiples medidas cautelares de la Corte Interamericana de Derechos Humanos que tenían varios pueblos indígenas del país, entre ellos:
- Comunidad páez, norte del Cauca, 1998.

- Comunidad zenú de Sotavento, Córdoba, 1996.

- Pueblo embera-katío, 2001.

- Consejo Regional Indígena de Caldas (CRIDEC), resguardos y asentamientos embera-chamí de Caldas y Risaralda, 2002.

- Pueblo pijao del Tolima, 2003.

- Pueblo wiwa de la Sierra Nevada de Santa Marta, 2005.

- Asociación de Cabildos Indígenas del Norte del Cauca, 2005.

- Consejo Regional Indígena del Cauca (CRIC), 2009.

- Asociación de Mujeres Campesinas, Negras e Indígenas de Colombia (Anmucic), 2001.

\section{G. Implicaciones del auto 004 de 2009 para los indígenas}

Antes de desarrollar las implicaciones que trajo el auto 004 para las comunidades indígenas colombianas, es importante subrayar algunos de los principales acápites de la ya famosa sentencia de tutela T-025 de 2004 de la Corte Constitucional. En este fallo judicial la Corte menciona dentro de los factores para definir si existe un estado de cosas inconstitucional:

(i) la vulneración masiva y generalizada de varios derechos constitucionales que afecta a un número significativo de personas; (ii) la prolon- 
gada omisión de las autoridades en el cumplimiento de sus obligaciones para garantizar los derechos; (ii) la adopción de prácticas inconstitucionales, como la incorporación de la acción de tutela como parte del procedimiento para garantizar el derecho conculcado; (iii) la no expedición de medidas legislativas, administrativas o presupuestales necesarias para evitar la vulneración de los derechos; (iv) la existencia de un problema social cuya solución compromete la intervención de varias entidades, requiere la adopción de un conjunto complejo y coordinado de acciones y exige un nivel de recursos que demanda un esfuerzo presupuestal adicional importante; (v) si todas las personas afectadas por el mismo problema acudieran a la acción de tutela para obtener la protección de sus derechos, se produciría una mayor congestión judicial.

Así mismo, la sentencia establece las circunstancias fácticas por las cuales la Corte considera que es viable determinar el estado de cosas inconstitucional en relación con el desplazamiento forzado.

Varios elementos confirman la existencia de un estado de cosas inconstitucional respecto de la situación de la población internamente desplazada. En primer lugar, la gravedad de la situación de vulneración de derechos que enfrenta la población desplazada fue expresamente reconocida por el mismo legislador al definir la condición de desplazado, y resaltar la violación masiva de múltiples derechos. En segundo lugar, otro elemento que confirma la existencia de un estado de cosas inconstitucional en materia de desplazamiento forzado, es el elevado volumen de acciones de tutela presentadas por los desplazados para obtener las distintas ayudas y el incremento de las mismas. En tercer lugar, los procesos acumulados en la presente acción de tutela, confirman ese estado de cosas inconstitucional y señalan que la vulneración de los derechos afecta a buena parte de la población desplazada, en múltiples lugares del territorio nacional y que las autoridades han omitido adoptar los correctivos requeridos. En cuarto lugar, la continuación de la vulneración de tales derechos no es imputable a una única entidad. En quinto lugar, la vulneración de los derechos de los desplazados reposa en factores estructurales enunciados en el apartado 6 de esta providencia dentro de los cuales se destaca la falta de correspondencia entre lo que dicen las normas y los medios para cumplirlas, aspecto que adquiere una especial dimensión cuando se mira la insuficiencia de recursos dada la evolución del problema de desplazamiento y se aprecia la magnitud del problema frente a la capacidad institucional para responder oportuna y eficazmente a él. En conclusión, la Corte declarará formalmente la existencia de un estado de cosas inconstitucional relativo a las condiciones de vida de la población internamente desplazada. Por ello, tanto las autoridades nacionales como las territoriales, dentro de la órbita de sus competencias, habrán de adoptar los correctivos que permitan superar tal estado de cosas.

Además de esto, la Corte Constitucional expresó en el fallo que en el universo de víctimas del desplazamiento forzado existían unos grupos de especial protección, dada la condición de extrema vulnerabilidad de la población desplazada, no solo por el hecho mismo del desplazamiento, sino también porque en la mayor parte de los casos se trata de personas especialmente protegidas por la Constitución -tales como mu- 
jeres cabeza de familia, menores de edad, minorías étnicas y personas de la tercera edad-.

Siguiendo esta línea y en vista del incumplimiento estatal, la Corte se vio obligada a proferir unos autos de seguimiento específicos para dichos grupos de especial protección; es de esta manera que surge el auto 004 de 2009, el cual pretende garantizar la pervivencia y supervivencia de 34 pueblos indígenas que para ese entonces consideró que se encontraban en riesgo de extinción física y cultural. ${ }^{3}$ Esta tarea se llevaría a cabo con la creación de planes de salvaguarda específicos para cada uno de los pueblos amenazados.

\section{H. ¿Qué dice el auto 004 de 2009?}

El auto 004 empieza caracterizando el clima de violencia sociopolítica, económica y cultural a la que han sido sometidos muchos pueblos indígenas con ocasión del conflicto armado interno que vive Colombia. Fundamentalmente hace una revisión de un listado de pueblos (34 para el 2009), que se encontraban en riesgo de extinción física y cultural producto del accionar de los diferentes grupos armados. La Corte, entonces, intenta a través del auto establecer un método que unifique las violaciones a los derechos humanos y el derecho internacional humanitario, planteándolo en cuatro grados de afectaciones: (1) confrontaciones que se desenvuelven en territorios indígenas entre los actores armados, sin involucrar activamente a las

3 La Corte Constitucional a través del auto 382 de 2010 decidió incluir a dos pueblos más (hitnú y macaguán) debido al grave peligro por desplazamiento forzado y desprotección estatal. comunidades indígenas y sus miembros, pero afectándolos directamente y las subcategorías o manifestaciones: a) incursiones y presencia de grupos armados ilegales en territorios indígenas, en ocasiones seguidas de una fuerte militarización del territorio por parte de la Fuerza Pública; b) confrontaciones armadas entre grupos armados ilegales, o entre estos y la Fuerza Pública, en territorios indígenas, o cerca de estos; c) ocupación de lugares sagrados por los grupos armados ilegales y por unidades de la Fuerza Pública; d) instalación de bases militares en territorios indígenas sin consulta previa; e) instalación de minas antipersonal y abandono de municiones sin explotar (MAP/MUSE) en sus territorios; muchos de los casos reportados de victimización por estos artefactos corresponden, de hecho, a personas pertenecientes a grupos indígenas. (2) Procesos bélicos que involucran activamente a los pueblos y comunidades indígenas, y a sus miembros individuales, en el conflicto armado; las subcategorías son: a) señalamientos; b) asesinato selectivo de líderes, autoridades tradicionales y miembros prominentes de las comunidades indígenas; c) amenazas; d) confinamientos de familias y comunidades enteras; e) controles sobre la movilidad de personas, alimentos, medicamentos, combustibles, bienes y servicios básicos y ayuda humanitaria de emergencia; f) irrespeto reiterado a las autoridades tradicionales indígenas por parte de los actores armados ilegales y, en ocasiones, por miembros de la fuerza pública; h) controles de comportamiento y de las pautas culturales propias por parte de los grupos armados ilegales; i) reclutamiento forzado de menores, jóvenes y miembros de la comunidad por actores armados 
irregulares; j) apropiación y hurto de bienes de subsistencia de las comunidades (cultivos, productos, animales, insumos básicos) por los actores armados ilegales y en algunos casos por la Fuerza Pública; k) prostitución forzada, violencia sexual y enamoramiento de mujeres y jóvenes indígenas como táctica bélica, principalmente por parte de los actores armados ilegales; I) homicidio, amenaza y hostigamiento de maestros, promotores de salud y defensores de los derechos de los indígenas por los actores armados irregulares; m) ocupación temporal de escuelas, viviendas y edificios comunitarios por los actores armados ilegales y, en ocasiones, por miembros de la Fuerza Pública; n) utilización de las comunidades como escudos humanos durante los enfrentamientos, por parte de los actores armados ilegales. (3) Procesos territoriales y socioeconómicos conexos al conflicto armado interno que afectan los territorios tradicionales $y$ las culturas indígenas, con las siguientes subcategorías: a) el despojo territorial simple por parte de actores con intereses económicos sobre las tierras y recursos naturales de propiedad de las comunidades indígenas; b) el desarrollo de actividades económicas lícitas o ilícitas en territorios indígenas; c) fumigaciones de cultivos ilícitos sin el lleno de los requisitos de consulta previa, y (4) Procesos socioeconómicos que, sin tener relación directa con el conflicto armado, resultan exacerbados o intensificados por causa de la guerra; sus subcategorías son: a) la pobreza y sus consecuencias; b) la inseguridad alimentaria y sus consecuencias; agravada por apropiación, destrucción por conflicto armado, restricciones de movilidad; c) condiciones de salud deterioradas que se agravan por el conflicto armado, en particular, mortalidad infantil alta, y altas tasas de enfermedades prevenibles; d) la invisibilidad preexistente por censos y estadísticas divergentes; e) el debilitamiento étnico y social y la aculturación prevalecientes. En este sentido todas las diversas afectaciones ocurridas a las comunidades indígenas deberían ajustarse a las subcategorías planteadas, con base en ello se crearían los planes de salvaguarda para cada pueblo. Estas categorías hacen parte de las consideraciones de la sentencia T-025 de 2004.

Las medidas a adoptar y sus componentes mínimos según el auto 004 de 2009 son: término máximo de seis (6) meses contados desde la notificación del presente auto, para que el Estado adopte decisiones coordinadas:

Primero, que diseñen e implementen, dentro de sus respectivas órbitas de competencia, un Programa de Garantía de los Derechos de los Pueblos Indígenas Afectados por el Desplazamiento, con el nombre que los responsables gubernamentales estimen aconsejable ponerle. Este programa deberá ser adoptado, junto con un cronograma para su implementación y seguimiento, dentro del término de seis (6) meses, y deberá contener componentes de prevención y atención así como respetar los criterios de racionalidad constitucional en las políticas públicas mencionadas en el presente auto y en otros donde se ha ordenado incluir un enfoque diferencial, en este caso en cumplimiento del principio de diversidad etnocultural. En el diseño de este programa se aplicarán los parámetros constitucionales de participación de las organizaciones que abogan por los derechos de los pueblos indígenas, así como de 
líderes de los pueblos indígenas más afectados por el desplazamiento. Los responsables de diseñar e implementar esta orden serán los mismos de la orden atinente a los planes de salvaguarda que se enuncia a continuación.

Segundo, que formulen e inicien la implementación de planes de salvaguarda étnica ante el conflicto armado y el desplazamiento forzado para cada uno de los pueblos identificados en la presente providencia.

Estos planes de salvaguarda étnica deben responder, tanto en el ámbito de la prevención del desplazamiento forzado como de la atención a sus víctimas a la crítica situación descrita para cada uno de los pueblos.

\section{Cumplimiento del auto 004 de 2009}

El mismo auto señala que la creación e implementación de los planes de salvaguarda será responsabilidad del director de Acción Social y del Ministerio del Interior y de Justicia, con la intervención de la directora del Instituto Colombiano de Bienestar Familiar (ICBF) en el ámbito de su competencia, el Ministerio de Educación, el Ministerio de Defensa y la dirección del Programa Acción Integral contra las Minas Antipersonales, por ser las autoridades responsables en el Sistema Nacional de Atención Integral de Población Desplazada (SNAIPD). Vale la pena mencionar que en la práctica la responsabilidad material ha quedado en manos del Ministerio del Interior.

Es indiscutible para muchos colombianos que el fenómeno del desplazamiento forzado y otros graves crímenes contra los pueblos indígenas se mantiene pese a la sentencia T-025 de 2004 y el auto 004 de 2009. Esto se evidencia en el auto 145 de 2013 expedido por la Corte Constitucional. De lo señalado puede inferirse que existe un incumplimiento del marco legal diseñado por la Corte Constitucional, además esta ha realizado un análisis de los referidos informes y, como resultado de este ejercicio, ha constatado que si bien el Gobierno Nacional ha adelantado distintas acciones encaminadas a atender y proteger a comunidades y pueblos indígenas cuya supervivencia se ve comprometida a raíz del desplazamiento al que son forzados directa e indirectamente, la crisis humanitaria en la que están inmersos sigue siendo de extrema gravedad. Así lo advirtió la Corte en el auto 219 de 2011, a través del cual hizo un seguimiento a las acciones adelantadas por el Gobierno Nacional para la superación del estado de cosas inconstitucional, donde concluyó que:

Situaciones como las que enfrentan algunos pueblos indígenas y comunidades afrocolombianas protegidas por los autos 004 y 005 de 2009, (...), muestran que su situación de seguridad ha empeorado y que a pesar de la gravedad de los hechos, no se han adoptado medidas adecuadas para la prevención del desplazamiento forzado y de otras graves violaciones a los derechos humanos. En los casos allí citados, ocurridos entre 2010 y principios de 2011, se puede verificar que entre los riesgos más recurrentes se encuentran los señalamientos y las amenazas a los líderes y autoridades indígenas por presunta militancia en grupos armados ilegales o prestar su colaboración a las instituciones del Estado, que derivan en asesinatos; también los enfrenta- 
mientos armados entre grupos al margen de la ley y la fuerza pública, dentro y fuera de su territorio, lo cual se traduce en riesgos exacerbados para estas comunidades, que en la mayoría de los casos generan desplazamientos masivos, trayendo consigo inseguridad alimentaria, enfermedades, pérdida de sus prácticas culturales tradicionales, conflictos internos e inter-étnicos, entre otros. Lo anterior, pone en evidencia que a pesar de las acciones desplegadas por el Gobierno Nacional, la problemática que aqueja a estos pueblos impone la adopción de medidas adicionales para hacerle frente a esta grave situación que aún no se ha logrado superar.

Este incumplimiento persiste actualmente y es una de las grandes deudas del gobierno Santos, como lo señala recientemente Baquero (2014, pág. 3) en la revista Semana, donde recuerda que hasta la fecha los planes de salvaguarda no han sido efectivos. De los 34 planes ordenados por la Corte, solo se han presentado nueve, los cuales no han sido implementados por falta de coordinación entre los diferentes órganos estatales y el incumplimiento de los acuerdos interinstitucionales. Los 25 planes restantes no han sido implementados por la poca concertación y la falta de recursos.

\section{METOdOLOGÍA}

\section{A. Para el trabajo de campo}

El enfoque metodológico que desarrollé fue de carácter cualitativo, definido por Ritz, (1977, pág. 48) como una investigación que produce datos descriptivos, según las propias palabras de las personas, en forma hablada o escrita, y la conducta observable.

Parafraseando al mismo autor resalto algunos de los principios del análisis cualitativo implementado a la hora de desarrollar el trabajo de campo (Baquero, 2014, pág. 3):

1. La investigación cualitativa es inductiva y desarrolla conceptos, intelecciones y comprensiones partiendo de pautas de los datos, y no recogiendo datos para evaluar modelos, hipótesis o teorías preconcebidas.

2. Perspectiva holística: las personas, los escenarios o los grupos no son reducidos a variables sino considerados como un todo.

3. La investigación cualitativa trata de comprender las personas dentro del marco de referencia de ellas mismas.

4. En el cualitativo todas las perspectivas son valiosas y objeto de análisis.

5. El método cualitativo es humanista, las personas no pueden constituirse en un dato estadístico, es con sus relatos e historias de vida pasada, presente y futura como se entreteje la investigación.

6. La validez de la investigación la constituye la estrecha relación entre los datos y lo que la gente realmente dice y hace.

En el mismo sentido es importante señalar que los instrumentos desarrollados para la recopilación de la información seguirán el mismo patrón del método cualitativo. 


\section{B. Instrumentos de socialización y diagnóstico auto 004 de 2009}

Como instrumento de diagnóstico con enfoque cualitativo llevado cabo para la recopilación de la información se encuentra:

\section{La entrevista (sakirra) semiestructurada}

Siguiendo la línea de Corbetta (2003, pág. 91), la entrevista tendría las siguientes características: a) provocada por el entrevistador; b) realizada a sujetos seleccionados a partir de un plan de investigación; c) en un número considerable; d) con una finalidad de tipo cognitivo; e) guiada por el entrevistador; y f) con un esquema de preguntas flexible y no estandarizado.

La entrevista semiestructurada sería, entonces, aquella en donde el investigador tiene unos temas establecidos, pero escoge libremente el orden y forma de plantear las preguntas al entrevistado. Para el caso del diagnóstico del Plan de Salvaguarda, consideré que esta estructura era la más indicada, ya que existen unos temas relevantes preestablecidos, ${ }^{4}$ para este caso, conocer si el pueblo wayuu de Riohacha ha sido víctima de alguno de los cuatro grados de afectación que desarrolla el auto 004 de 2009.

Por otro lado Guber (2001) señala que es perfectamente factible relacionar la entrevista cua-

4 La metodología aplicada no es propiamente de entrevistas profundas, ya que debido al cronograma establecido se diseñó una única entrevista dirigida a las personas más importantes de las comunidades (autoridad ancestral, etnoeducadores, líderes espirituales, líderes sociales). litativa con el marco interpretativo de la acciónparticipante ya que en sus palabras "La entrevista es una situación cara-a-cara donde se encuentran distintas reflexividades pero, también, donde se produce una nueva reflexividad" (pág. 30). Entonces, la entrevista es una relación social a través de la cual se obtienen enunciados

y verbalizaciones en una instancia de observación directa y de participación. La entrevista y la observación participante pueden según Taylor y Bodgan (1977, pág. 50) ser armonizadas y complementarias, aunque el canon investigativo afirme que el primero sería situado en un lugar preparado (entrevista) y en el otro enfoque el investigador lo adelanta directamente en el trabajo de campo (observación participante).

Las entrevistas fueron en total dieciocho, todas obtenidas en los territorios ancestrales del municipio de Riohacha; entre los entrevistados se encuentran pütchipüs, oütsu, líderes sociales, educativos, autoridades tradicionales y jóvenes. Los diálogos se sostuvieron en español, y en wayúunaiki cuando los entrevistados eran monolingües, en cuyo caso fueron traducidas por el equipo wayuu que apoyaba el diagnóstico de los territorios ancestrales.

2. Cartografía social (shiakua wouumaiinpa)

La cartografía social en palabras de Mora y Jaramillo (2003, pág. 10) se define como:

Una metodología de trabajo en grupo que permite la realización de diagnósticos participativos como resultado del reconocimiento del 
territorio a través de distintos mecanismos: la observación, conversatorios comunitarios, acercamientos a realidades específicas, visitas de campo, entrevistas, revisión de documentos y otras ayudas que permitan un conocimiento lo más preciso posible acerca del lugar, las relaciones y las condiciones de vida de quienes habitan, frecuentan, trabajan y conocen una zona, o región, todas las cuales se plasman en el mapa del territorio que se va a reconstruir.

Este instrumento de enfoque cualitativo hace parte generalmente de la investigación acciónparticipación, ya que su esencia es recopilar, desde diferentes escenarios, las preocupaciones sociales de los sectores más marginados por la sociedad mayoritaria, como ocurre recurrentemente en Colombia, lo que Borda (1984, pág. 23) llegaría a pretender como la ciencia del pueblo.

\section{Ventajas de la cartografía social (shiakua wouumaiinpa)}

- Todos los saberes son válidos y necesarios para la transformación del territorio.

- La cartografía es una producción colectiva del conocimiento.

- Es una práctica socialmente comprometida.

- El territorio es interrelacionado con todas las dimensiones culturales, políticas, sociales, económicas y ambientales, entre otras.

Para la realización del diagnóstico tuve en cuenta varias de las ventajas señaladas, puesto que es prioritario reconocer las múltiples dimensiones del saber en el marco de un verdadero diálogo intercultural; en este caso se cumple con los presupuestos establecidos por el auto 004 de 2009, en relación con la creación de los diagnósticos del Plan de Salvaguarda a partir de la lengua y conocimientos propios.

En este orden, se constituyó para mí en una práctica comprometida, ratificando cómo las comunidades indígenas han sido estigmatizadas, criminalizadas, utilizadas; por ende, el diagnóstico pretende contribuir a reflejar las principales afectaciones sufridas como pueblo wayuu, en el contexto del conflicto armado interno que padece Colombia.

El concepto de territorio, tan prioritario para la cosmogonía indígena, se ve interrelacionado con todo el escenario en el que se desenvuelve la vida de las comunidades wayuu, por tanto permite tomar un diagnóstico y unas posibles alternativas de manera integral.

En total se realizaron 65 cartografías que cubrieron a cada comunidad del territorio ancestral del municipio de Riohacha, durante dos meses de trabajo de campo. Para lograr una mejor ilustración se utilizaron marcadores con diferentes colores que representaban el grado de afectación: color negro para identificaciones del lugar, historia y otras descripciones; color rojo para situaciones en que los wayuu se hayan visto violentados de manera directa o indirecta por los actores armados; color verde para señalar problemáticas relacionadas con agricultura, territorios, zonas de reserva ecológica; color azul 
para problemáticas relacionadas con la falta de agua y ubicar reservas acuíferas del terreno.

En este orden de ideas, la metodología para presentar el trabajo de campo consiste en relacionar las situaciones encontradas y encauzarlas en los cuatro tipos de afectaciones que desarrolla la Corte Constitucional en el auto 004, a través de las entrevistas y cartografías ya reseñadas.

\section{RESULTADOS EN EL PROCESO DE INVESTIGACIÓN}

Como se puede inferir de los cuatro grados de afectación descritos en el auto 004 de 2009, los dos primeros establecen el impacto generado por los actores del conflicto armado, de manera indirecta y directa; los dos restantes determinan la relación del conflicto armado con elementos de tipo social, económico, cultural, político, todos necesarios para concluir cuáles son los verdaderos problemas estructurales y las posibles soluciones, lo cual debe hacerse a la sukuaipa wayuu (a la manera wayuu).

\section{A. Categoría 1. Las confrontaciones que se desenvuelven en territorios indígenas entre los actores armados, sin involucrar activamente a las comunidades indígenas y sus miembros, pero afectándolos en forma directa y manifiesta}

En este primer grado de afectación, la circunstancia más recurrente hallada fue la subcategoría a) Incursiones y presencia de grupos armados ilegales en territorios indígenas, en ocasiones seguidas de una fuerte militarización del territorio por parte de la Fuerza Pública. Esto ha ocurrido fundamentalmente en la vía que comunica a Valledupar con Riohacha, donde los grupos armados han mantenido una presencia constante porque sirve como corredor estratégico para escapar a las faldas de la Sierra Nevada. Los wayuu han denominado a los guerrilleros del frente 59 de las FARC unainkuinjatka, es decir, los que viven entre el monte. Igualmente hubo presencia hasta el 2007 de maleea, en español "paraco", que en wayuunaiki representa el comúnmente Ilamado panal de abejas. Esta connotación de la palabra pudiera también representar la picadura de las abejas, como analogía con el accionar y peligrosidad de los paramilitares, según la versión dada por wayuus que viven en Riohacha. De igual manera, a la fuerza pública que ha tenido presencia en este territorio se le ha denominado "cachacos", sin embargo, no es una expresión propia del wayuunaiki sino más bien un vocablo utilizado por las comunidades de la costa afectada por hombres del altiplano, como alguna vez lo evidenciara en su autobiografía el hoy fallecido Gabriel García Márquez.

Dentro de las comunidades más afectadas por la presencia de los actores armados se encuentran los corregimientos de Juan y Medio y Cotoprix. Las entrevistas realizadas a más de veinte autoridades tradicionales ratifican esto, y las cartografías efectuadas por los miembros de las comunidades narran la presencia y el grado de afectación que provocó en ellas; pese a lo expuesto, el impacto en materia de graves crímenes de lesa humanidad, violaciones a los 
derechos humanos e infracciones al derecho internacional humanitario no resultó tan catastrófico como pudo haber sido. Sin embargo, es importante señalar en este punto que la Corte Constitucional en el auto 004, así como en sendas sentencias ha ratificado la prevalencia del territorio como un derecho en sí, por tanto la intromisión de los grupos asociados al conflicto armado se presenta como una violación por sí misma, que se constituye en una amenaza para la pervivencia y supervivencia cultural y física.

\section{B. Categoría 2. Los procesos bélicos que involucran activamente a los pueblos y comunidades indígenas, y a sus miembros individuales, en el conflicto armado}

En este ítem las situaciones más recurrentes tienen que ver con las violaciones a los derechos humanos y violación al derecho internacional humanitario. En este sentido la narración descriptiva se sustenta en la categoría del crimen y los testimonios que los soportan.

Así, por ejemplo, la autoridad de Disfruta OrguIlo, nos contó que todos sus padecimientos son un reflejo del sufrimiento que han soportado en medio del conflicto armado:

Fue un hecho que nos sucedió en donde mis hijos quedaron traumatizados, un hecho donde casi me matan a mí y a mis hijos, me tocó salir desplazada de allá con mis hijos, ellos primero tuvieron un enfrentamiento con la guerrilla, este caso sucedió en la Sierra donde vivíamos con los aruhacos, nosotros estábamos viviendo en una finquita y allí llegaron los paramilitares (maleea-kooi), se les dice así porque paraco es para nosotros el panal de las abejas piconas, y nos dijeron que éramos parte de la guerrilla (unainkuinjatka), les decimos así porque son los que permanecen en el monte espeso y entonces nos destruyeron toda la casa, la ropa, todas las cosas y después tuvimos que subir más a la Sierra y nos devolvimos para la Sierra, en la vía había muchos muertos y de allí mataron al papá de mis hijos y quedé viuda con 4 niños (entrevista personal, febrero 28 de 2014).

Siguiendo esta misma línea, en la comunidad de Al Jote se pone de manifiesto la presencia de los diferentes actores armados y cómo los wayuu se ven involucrados en una violencia que no terminan de comprender. Así lo reveló en su narración un habitante de dicha comunidad:

En horas de la noche, como de 9 a 10 de la noche, la familia se había acostado, todo estaba oscuro y silencioso, solo los perros empezaron a ladrar, cuando de repente tocaron la puerta; mi esposo preguntaba quiénes eran y a él le dijeron que era de parte de la Fiscalía. Él contestó que la Fiscalía no hace requisas por la noche, entonces mi esposo Benjamín Quintana dijo: quizás son mis cuñados que están molestando y fue cuando salió a abrirles. Yo le pedía que no saliera de casa; le dije eso porque habían tocado la puerta duro pero él insistió que eran sus cuñados que estaban bebiendo esa noche. Porque tocaban tan duro la puerta me asusté. Él salió y yo salí detrás de él cuando veo muchos. Aproximadamente como unos 20 sujetos y con armas de largo alcance, no podía identificar si era la policía o la Fiscalía como dijeron ellos porque estaba muy oscuro, y le di- 
jeron: date vuelta para una requisa, mis hijos salieron en ese momento; lo matan de espalda delante de mí y mis hijos. Ellos se fueron y no dijeron nada, me lo dejaron ahí tirado en el suelo, no sabía qué hacer en ese momento, solo abracé a mis hijos cuando lo observaban en el suelo ahí tirado, ellos se marcharon y no dijeron nada, nunca supe por qué me lo mataron, él nunca me dijo que tenía problemas con nadie y mucho menos tenía amenazas porque él era una persona buena. Todavía no entiendo por qué lo mataron, he tenido que ser mamá y papá para mis hijos, no sé qué decir cuando me preguntan por qué lo mataron (entrevista personal, marzo 5 de 2014).

Otro fenómeno recurrente en este sentido ha sido el desplazamiento individual y colectivo, como por ejemplo el vivido por la familia de la autoridad de los hermanos wayuu de AlewaLos Monos (que significa en amistad con los monos), los mismos que me despertaron a eso de las cuatro de la mañana y me expusieron su caso:

En el año 2000 empezó a llegar la gente del monte, eran los paramilitares (maleea), primero comenzamos a negociar con ellos nuestro ganado, luego nos pidieron dinero porque decían que ellos nos cuidaban, fue entonces cuando asesinaron cuatro vecinos de la comunidad, a uno de ellos, le mocharon la cabeza y la dejaron en un tronco, fue un momento muy doloroso, de mucha amargura para nosotros, vimos que todas las personas del corregimiento salieron desplazadas ese mismo día, poco después nos dijeron que solo quedábamos nosotros, que estábamos en fuego cruzado por la guerrilla y los paramilitares, a los tres días salimos nuestras once familias buscando un me- jor futuro (Obencio y Ramón Uriana, entrevista personal, 25 de marzo de 2014).

En las cartografías de estos territorios es preeminente el trazo del marcador rojo, ya que ha sido un fenómeno recurrente a lo largo de los años; también es frecuente encontrar que otros actores como la delincuencia común han hecho presencia reiterativamente. Por otra parte, en el municipio de Riohacha y especialmente en el sector rural, en no pocas ocasiones se han presentado robos de wayuus hacia otros de la misma etnia, en un proceso de aculturación y ante la precariedad en el sustento económico de una zona de por sí bastante marginada por el Estado colombiano.

\section{Categoría 3. Los procesos territoriales y socioeconómicos conexos al conflicto armado interno que afectan sus territorios tradicionales y sus culturas}

Como había mencionado antes, las categorías 3 y 4 que reconoce la Corte Constitucional no tienen una necesaria relación directa con el conflicto armado. Esto se ha presentado, en mi percepción, a partir de la compleja situación de Ios actores armados que hacen presencia y, por tanto, afectan las comunidades indígenas. Para este caso, uno de los más sensibles y complejos escenarios que padecen los territorios ancestrales es el despojo de territorios (en el auto no se caracteriza que el agresor deba ser uno de Ios actores del conflicto). Este tipo de circunstancias se presentan en la mayoría del territorio rural de Riohacha; también es recurrente el desarraigo cultural que afrontan las comunidades, en parte por su proximidad con la capital del de- 
partamento, pero también por conflictos presentados con otros habitantes, como por ejemplo, con los afrodescendientes.

Las afectaciones territoriales encontradas tienen que ver, entre otras, con la falta de territorio, legalización de títulos, despojo de tierras (alejuuna saouje maa) por parte de colonos y áreas no resguardadas.

Entre los distintos testimonios se puede encontrar lo que me contó Carlos Uriana, líder social wayuu de los territorios ancestrales, sobre lo arduo que ha sido el proceso para solicitar que el territorio sea reconocido como resguardo, sin conseguirse plenamente:

Desde el año 1997 iniciamos un arduo y difícil proceso de constituir un cabildo en los territorios ancestrales, que eran la mayoría de las rancherías en Riohacha. La Alcaldía decía que yo estaba equivocado, pero seguí en mi proceso, logramos asesoría de algunos alijunas de buen corazón, nos independizamos y conocimos el programa que va dirigido a las comunidades indígenas. Para la Alcaldía, antes de 1993, solo existían siete resguardos, no quería admitir más comunidades porque ellos repartían sus intereses entre estos resguardos. Esto ha traído problemas para mí y mi familia, incluso me han declarado objetivo militar (entrevista personal, 27 de marzo de 2014).

Por otro lado, la autoridad de Guanabanal me comentaba que no tiene un certificado del título adjudicado por el Incoder. Él me explicó cómo otras muchas comunidades no poseen registro de título, únicamente han habitado el territorio desde mucho tiempo atrás.
En otros casos como en Plowsirra, el terreno es decididamente insuficiente en comparación con el necesario para que las familias wayuu vivan satisfactoriamente con calidad de vida. En este mismo territorio los wayuu han tenido que mudarse para Riohacha y venir de manera ocasional a los territorios.

Así mismo, son varias las afectaciones culturales que padecen los wayuu, y principalmente tienen que ver con la occidentalización de las costumbres. Entre las más amenazadas podemos encontrar: pérdida de la lengua, vestuario, costumbres, uso de la drogadicción, desuso de medicina tradicional, desuso de la figura del pütchipu y la oütsu. En particular conocí el testimonio de la oütsü María Jusayú, quien me decía:

Somos pocas las oütsü que yo conozco en Riohacha, solo sé de cuatro incluyéndome, es un don que vamos adquiriendo, uno se enferma, hasta que una oütsü le incorpora los espíritus con que va a trabajar, ahora el evangelio cura todo y se está acogiendo, en todas las partes, ven la otüsü como cosa del diablo, yo no veo realmente mucha diferencia con mis creencias, ya que también creo en Dios y para eso se requieren ciertas ceremonias, lo mismo que yo hago (entrevista personal, 19 de marzo de 2014).

He clasificado este desarraigo desde el punto de visto violento y no violento.

\section{Punto de vista violento}

Un ejemplo de este caso lo encontramos al visitar la comunidad de Los Cocos, que se encuen- 
tra muy cerca del corregimiento de Moreneros. En este sector Existe una gran discriminación hacia los wayuu de este territorio, lo que ha originado rechazo, agresiones verbales y físicas:

Es mucha la discriminación que sufrimos por parte de los alijunas, los niños son estigmatizados, no tienen educación propia, han existido agresiones a wayuus, a una señora una vez le dieron un veneno que casi la mata (autoridad de Los Cocos, entrevista personal, 12 de marzo de 2014).

\section{Punto de vista no violento}

Para contextualizar este punto de vista usaré el testimonio de una joven de la comunidad del corregimiento Juan de Aragón, quien me explicó cómo las condiciones geográficas del municipio hacen que el desarraigo cultural sea extremo. Esto se refleja en el proceso a que se ven abocados los jóvenes wayuu al tener sobre sus espaldas, por un lado, la responsabilidad del legado cultural y, por otro lado, sobrellevar la influencia alijuna tan marcada que termina por incidir en los más jóvenes. Estas fueron sus palabras:

Ser wayuu para mí significa que tenemos prioridad en cuanto al estudio y poder salir adelante, no me da pena decir que soy wayuu, hoy no tengo una manta puesta porque no tengo y la verdad no me nace ponérmela, me la coloco tal vez aquí pero en Riohacha no, o solamente me la coloco en ocasiones como en un velorio, pero que las tenga como las demás ropas no, además me siento más cómoda con la ropa occidental que con las mantas. Ya me gradué hace dos años del colegio Liceo Nacional Almirante Padilla pero por falta de recursos econó- micos no he podido ingresar a la universidad, cuando estaba en primaria sí me enseñaban wayuunaiki pero cuando pasé para bachillerato me lo dejaron de enseñar (entrevista personal, 2 de abril de 2014).

Sin embargo, el panorama cultural no se encuentra en un estado de extrema urgencia. En las cartografías sociales se visualiza que las personas aún practican ciertos bailes típicos como la jonna, la mayoría de los habitantes en rancherías hablan wayuunaiki y las mujeres siguen elaborando chinchorros y mochilas con motivos totémicos, propios de sus raíces culturales.

\section{Categoría 4. Procesos socioeconómicos que, sin tener relación directa con el conflicto armado, resultan exacerbados 0 intensificados por causa de la guerra}

Algunas de las afectaciones más importantes a nivel socioeconómico la padecen los wayuu que se ubican en el sector vía a Santa Marta. La más notoria carencia es el agua potable; el sector, al parecer, ha sido históricamente abandonado por el Estado, situación que se vuelve más difícil debido a las condiciones del suelo erosionado. El contexto socioeconómico puede estar ubicado en el marco de la afectación causada por la agudización de las condiciones preexistentes, como lo es la pobreza de estas comunidades, producida esencialmente por la posible negligencia estatal, así como por factores asociados a la extracción de los minerales que se encuentran en el subsuelo del territorio. La comunidad señaló en la cartografía social como principales soluciones, la construcción de molinos de agua, 
y jagüeyes para que sobrevivan sus animales y la familia. El agua es su necesidad más urgente, de hecho el día que fuimos con el equipo debimos postergar el trabajo hasta el día siguiente porque las autoridades y habitantes de la zona estaban protestando contra la Alcaldía de Riohacha por la falta de agua. ${ }^{5}$

En la plazoleta los asistentes comentaban que fueron embaucados por las exploraciones sísmicas realizadas por Ecopetrol. Esto explica la desconfianza que sintieron frente al proceso del Plan de Salvaguarda, porque pensaban que este provenía de un interés político local. ${ }^{6}$

Otra de las afectaciones socioeconómicas encontradas es la inseguridad alimentaria. A esta se le ha dado un despliegue importante después de la acción de tutela impetrada por el director de Planeación de La Guajira, el señor César Arismendi, contra el Estado colombiano. Según la noticia, 4171 menores murieron por desnutrición en La Guajira entre el 2008-2013, de ellos cerca de 3000 niños serían wayuus (Diario del Norte, 1 de abril de 2014, pág. 1).

La situación apenas se está conociendo, pero parece mucho más alarmante que la hasta ahora descrita, y que se dio a conocer a la luz pú-

5 Días antes de terminar el primer borrador de este artículo se publicó en el periódico regional Al Día, la noticia de cinco comunidades correspondientes al territorio ancestral de Riohacha que se encontraban en emergencia por la falta de agua.

6 Aquí se viene propiciando, según algunos entrevistados, una especie de acercamiento amistoso por parte de Ecopetrol, empresa que viene financiando actividades para las comunidades como el baile de la jonna, evento en que a cada autoridad le suministraron 1400000 , sin embargo, esto ha comenzado a generar disputas por la decisión de recibir o no estos dineros. blica en el programa Especiales Pirry del 06 de abril de $2014 .^{7}$ Es más, en otra noticia se reabre la controversia por las muertes por desnutrición de dos niños wayuu (Diario del Norte, 8 de abril de 2014, pág. 20).

En la cartografía social, para el caso de la vía Riohacha-Santa Marta, el marcador azul, indicativo de problemas que tienen que ver con el agua, se mezcla con el marcador verde, usado para señalar problemas relacionados con territorios y cultivos, es decir, el desabastecimiento genera dificultades a la hora de obtener alimentación a través de los cultivos, lo cual se agrava con la sequía que actualmente padece el departamento.

\section{CONCLUSIONES}

El primer elemento que debo señalar es que las circunstancias en las que se encuentran las comunidades wayuu son precarias y difíciles de caracterizar. En el trabajo de campo se mostraron como dificultades el que las autoridades tradicionales solo hablan wayuunaiki; la desconfianza extrema con los alijuna (los no wayuu), a raíz de la explotación, engaño y manipulación a la que se han visto abocados desde mucho tiempo atrás, por no decir que desde siempre, en la relación centro-periferia (De Sousa, 2010) del Estado colombiano. Sin embargo, el trabajo

\footnotetext{
7 En mi trabajo de campo pude palpar grandes problemas de desnutrición en la comunidad de Buenos Aires, los niños permanecen en condiciones muy adversas, su acceso al agua potable y la seguridad alimentaria se encuentra en peligro.
} 
de campo arrojó algunos resultados interesantes que paso a describir en tres conclusiones:

1. El conflicto armado en Riohacha no ha sido tan intenso como el ocurrido a otras comunidades indígenas wayuu. Sin embargo, allí han confluido todos los actores legales e ilegales que han mantenido un estado permanente de violencia en la región. De todos modos, lo claro es que son las afectaciones socioeconómicas (recrudecimiento de la pobreza) y el despojo territorial, los problemas más recurrentes. En la visita a las rancherías se vio que esta situación no es propia del siglo XXI, sino producto de una histórica ausencia estatal, que sigue presente hasta nuestros días.

2. El auto 004 de 2009 de la Corte Constitucional, que busca generar planes de salvaguarda para los pueblos indígenas víctimas del desplazamiento forzado y que hace parte del seguimiento a la sentencia T-025 de 2004, ha generado en mi opinión un efecto positivo en algunas comunidades. Así mismo, es importante reconocer cómo la Corte ha dado pasos efectivos en materia de jurisdicción especial indígena en distintas sentencias (Bonilla, 2006, pág. 267), sin embargo están muy lejos de representar un verdadero plan para preservar a los pueblos de una extinción física y cultural, asegurando su pervivencia y sobrevivencia. Fiel reflejo de esto son los numerosos autos que la Corte Constitucional ha expedido para que se le dé cumplimiento a la sentencia de tutela, sin que hasta ahora se haya logrado superar el estado de cosas inconstitucional de ninguno de los grupos de especial protección que reconoció este fallo. Por otra parte, aunque se hayan realizado numerosos diagnósticos de Plan Salvaguarda en varias comunidades, a la fecha no se ha implementado el primero en la práctica, lo que genera serias dudas sobre la voluntad del Ejecutivo por acatar en todas sus dimensiones esta trascendental sentencia.

3. La Corte Constitucional en el mencionado auto identificó cuatro grados de afectaciones relacionadas con el conflicto armado interno, y las categorías tres y cuatro parecen un esfuerzo por comprender la magnitud del problema y la interrelación entre el accionar bélico, los procesos de despojo de tierras y las afectaciones socioeconómicas; este reconocimiento es importante sobre todo al dejar abierta la interpretación del sujeto que genera las afectaciones, es decir, actores armados, no armados, legales e ilegales. Pese a esto, dicha categorización resulta en muchos casos incomprensible para las autoridades wayuu, además deben hacerse esfuerzos para incluir circunstancias que estén por fuera de lo expuesto en el auto 004.

\section{Referencias}

Baquero, C. A. (26 de junio de 2014). Las deudas de Santos. Recuperado el 10 de septiembre de 2014, de Semana: http://www.semana.com/opinion/articulo/santos-sus-deudasopinion-de- 
Bonilla Maldonado, D. (2006). La Constitución multicultural. Bogotá: Siglo del Hombre Editores/Universidad de los Andes.

Corporación Colectivo de Abogados José Alvear Restrepo. (2009). Elementos sobre la situación de derechos civiles y políticos de los pueblos indígenas en Colombia. Bogotá, Colombia: CCAJAR.

Corbetta, P. (2003). Metodología y técnicas de la investigación social. En K. Batthyány y M. Cabrera (Coords.), Metodología en investigación en Ciencias Sociales. Apuntes para un curso inicial. Montevideo: Comisión Sectorial de la Enseñanza (CSE) de la Universidad de la República.

Corporación para la Defensa y Promoción de Ios Derechos Humanos (Reiniciar). (2009). Notas para la presentación al Relator Especial de Naciones Unidas sobre la situación de los derechos de los pueblos indígenas, señor James Anaya, acerca del estado de cumplimiento de las Medidas Cautelares/ Provisionales del SIDH y de la criminalización de sus protestas y líderes.

Corte Constitucional de Colombia. Sentencia T-025 de 2004 (M. P.: Manuel José Cepeda Espinosa: enero 22 de 2004).

Diario del Norte. (1 de abril de 2014). Contencioso admite tutela en contra del Estado por muerte de 4.171 menores en la Guajira.

Diario del Norte. (8 de abril de 2014). Se reabre debate sobre muertes por desnutrición.
Guber, R. (2001). La etnografía, método, campo y reflexividad. Bogotá: Grupo Editorial Norma.

Guerra, W. (2002). La disputa y la palabra: la ley en la sociedad wayuu. Bogotá: Ministerio de Cultura.

Guerrero Barriga, S. (26 de marzo de 2014). Tutela por la muerte de 2969 niños en la Guajira. Obtenido de elheraldo.co: http://www. elheraldo.co/la-guajira/tutela-por-la-muertede-2969-ninos-en-la-guajira-147291

Herreño Hernández, A. L. (2004). Evolución política y legal del concepto de territorio ancestral indígena en Colombia. Revista El Otro Derecho, (31-32), 247-272.

Jaramillo, E. (2003). Territorio, identidad étnica y Estado. Asuntos Indígenas, (4).

Mora Páez, H. y Jaramillo, C. (Noviembre, 2003). Aproximación a la construcción de cartografía social a través de la geomática. Informática (11).

Observatorio del Programa Presidencial de Derechos Humanos y DIH. (2010). Diagnóstico de la situación del pueblo indígena wayúu. Recuperado de histotico.derechoshumanos. gov. co: http://historico.derechoshumanos.gov. co/Observatorio/Documents/2010/Diagnosticolndigenas/Diagnostico_WAY\%C3\%9AU.pdf

Organización Nacional Indígena de Colombia. (2009). Situación de los pueblos indígenas de Colombia. Bogotá: Instituto de Estudios para el Desarrollo y la Paz (Indepaz). 
Perrin, M. (1984-1985). La ley guajira: justicia y venganza entre los guajiros. Revista Cenipec, (9), 83-118.

Picon, F. R, (1996). From Blood Price to Bridewealth. System of Compensation and Circulation of goods among the Guajiro Indians (Colombia and Venezuela). En U. Fabietti y C. Salzman (eds.), The Anthropology of Tribal and Peasant Pastoral Societies (pp. 307-319). Colegio Ghislieri.

Rist, R. C. (1977). The Urban School: A Factory for Failure. Cambridge, Mass.: Mit Press.
Saler, B. (1986). Principios de compensación y el valor de las personas en la sociedad Guajira. Montalbán (17), 53-65.

De Sousa Santos, B. (2010). Descolonizar el poder, reinventar el poder. Montevideo: Editorial Trilce.

Tailor, S. J. y Bodgan, R. (1987). Introducción a los métodos cualitativos de investigación. (J. Piatigorsky, Trad.). Barcelona: Paidós. 